\title{
The draft genome of horseshoe crab Tachypleus tridentatus reveals its evolutionary scenario and well-developed innate immunity
}

Yan Zhou ${ }^{1,2^{*}}$, Yuan Liang ${ }^{1}$, Qing Yan ${ }^{2}$, Liang Zhang ${ }^{2}$, Dianbao Chen ${ }^{3}$, Lingwei Ruan ${ }^{4}$, Yuan Kong ${ }^{3}$, Hong Shi ${ }^{4}$, Mingliang Chen ${ }^{4^{*}}$ and Jianming Chen ${ }^{3,5^{*}}$ (D)

\begin{abstract}
Background: Horseshoe crabs are ancient marine arthropods with a long evolutionary history extending back approximately 450 million years, which may benefit from their innate immune systems. However, the genetic mechanisms underlying their abilities of distinguishing and defending against invading microbes are still unclear.

Results: Here, we describe the $2.06 \mathrm{Gbp}$ genome assembly of Tachypleus tridentatus with 24,222 predicted proteincoding genes. Comparative genomics shows that T. tridentatus and the Atlantic horseshoe crab Limulus polyphemus have the most orthologues shared among two species, including genes involved in the immune-related JAK-STAT signalling pathway. Divergence time dating results show that the last common ancestor of Asian horseshoe crabs (including T. tridentatus and C. rotundicauda) and L. polyphemus appeared approximately 130 Mya (121-141), and the split of the two Asian horseshoe crabs was dated to approximately 63 Mya (57-69). Hox gene analysis suggests two clusters in both horseshoe crab assemblies. Surprisingly, selective analysis of immune-related gene families revealed the high expansion of conserved pattern recognition receptors. Genes involved in the IMD and JAK-STAT signal transduction pathways also exhibited a certain degree of expansion in both genomes. Intact coagulation cascade-related genes were present in the $T$. tridentatus genome with a higher number of coagulation factor genes. Moreover, most reported antibacterial peptides have been identified in T. tridentatus with their potentially effective antimicrobial sites.
\end{abstract}

Conclusions: The draft genome of T. tridentatus would provide important evidence for further clarifying the taxonomy and evolutionary relationship of Chelicerata. The expansion of conserved immune signalling pathway genes, coagulation factors and intact antimicrobial peptides in T. tridentatus constitutes its robust and effective innate immunity for self-defence in marine environments with an enormous number of invading pathogens and may affect the quality of the adaptive properties with regard to complicated marine environments.

Keywords: Tachypleus tridentatus, Genome, Evolution, Innate immunity, Coagulation

\footnotetext{
*Correspondence: zhouy@fudan.edu.cn; mlchen_gg@tio.org.cn;

chenjianming@tio.org.cn

'State Key Laboratory of Genetic Engineering, School of Life Sciences, Fudan

University, Shanghai 200438, China

${ }^{4}$ State Key Laboratory Breeding Base of Marine Genetic Resources, Fujian

Collaborative Innovation Center for Exploitation and Utilization of Marine

Biological Resources, Third Institute of Oceanography, Ministry of Natural

Resources, 184 University Road, Xiamen 361005, China

${ }^{3}$ Institute of Oceanography, Minjiang University, Fuzhou 350108, China

Full list of author information is available at the end of the article
}

(c) The Author(s). 2020 Open Access This article is distributed under the terms of the Creative Commons Attribution 4.0 International License (http://creativecommons.org/licenses/by/4.0/), which permits unrestricted use, distribution, and reproduction in any medium, provided you give appropriate credit to the original author(s) and the source, provide a link to the Creative Commons license, and indicate if changes were made. The Creative Commons Public Domain Dedication waiver (http://creativecommons.org/publicdomain/zero/1.0/) applies to the data made available in this article, unless otherwise stated. 


\section{Background}

Horseshoe crabs are marine arthropods, representing an ancient family with an evolutionary history record extending back approximately 450 million years [1]. Based on their static morphology and their position in the arthropod family tree, they have been therefore labelled "living fossils" for a long time [2]. There are now few types of existing horseshoe crabs with narrow distribution.

Tachypleus tridentatus (Leach, 1819), an extant horseshoe crab species, is mainly distributed from coastal Southeast China to western Japan and in a few islands in Southeast Asia [3]. Similar to other invertebrates, T. tridentatus relies entirely on its innate immune system, including haemolymph coagulation, phenoloxidase activation, cell agglutination, release of antibacterial substances, active oxygen formation and phagocytosis [4-8], which operates on pattern-recognition receptors (PRRs) upon the detection of pathogen-associated molecular patterns (PAMPs) present on surface of microbes, such as lipopolysaccharides, lipoproteins and mannans [9]. Upon recognition, PRRs trigger diverse signal transduction pathways, including the Toll pathway, IMD pathway, JAK-STAT and JNK pathways, that can produce immune-related effectors [10]. Previous studies have investigated important signalling pathways and gene families from other arthropods, such as insects, crustaceans and myriapods, revealing extensive conservation and functional diversity among innate immune components across arthropods [11, 12]. Currently, the immune molecular mechanisms of how horseshoe crabs achieve distinguishing "self" and "non-self" antigenic epitopes, also known as pathogen-associated molecular patterns (PAMPs), has not yet been established.

The Atlantic horseshoe crab, Limulus polyphemus (Linnaeus 1758), is the most extensively investigated species of horseshoe crabs, occupying a large latitudinal range of coastal and estuarine habitats along the west Atlantic coast from Maine to Florida in eastern North America and along the eastern Gulf and around the Yucatán peninsula of Mexico [3, 13, 14]. A previous research about the genome of $L$. polyphemus with a high assembly quality has published, focusing on the full repertoire of Limulus opsins, which could provide insight into the visual system of horseshoe crabs [15]. In order to obtain the genome characteristics not only of $T$. tridentatus but also of the xiphosuran lineage and try to reduce errors of only using a single draft-quality genome, the comparative genomic study of immune systems within T. tridentatus and L. polyphemus were included.

Here, we present an analysis of the $T$. tridentatus genome sequence together with comparative genomic and divergence time analyses on other available Chelicerata genomes to date, including the previously released $L$. polyphemus assembly [15]. Particular attention was paid to gene families related to assessing the genomic and phenotypic changes of horseshoe crabs, as well as exploring immune signalling pathways, antimicrobial peptides and coagulation factors that may contribute to their robust and effective innate immunity for selfdefence in marine environments with enormous number of invading pathogens and may have important implications for the continuation of this species.

\section{Results}

\section{General genome features}

The genomic DNA isolated from $T$. tridentatus was sequenced to $124 \times$ coverage and assembled into a 2.06-Gb genome. The k-mer analysis yielded an estimated genome size of $2.22 \mathrm{~Gb}$ with a depth peak of $78 \times$. The final draft assembly consists of 143,932 scaffolds with an N50 scaffold size of $165 \mathrm{~kb}$, among which the longest scaffold size is $5.28 \mathrm{Mb}$ and the shortest is $1 \mathrm{~kb}$. The GC content of the genome is $32.03 \%$ (Table 1 ). A total of 24,222 protein-coding genes were conservatively predicted in the $T$. tridentatus genome in this study. The average exon and intron lengths predicted for the assembly are $333 \mathrm{bp}$ and $3792 \mathrm{bp}$, respectively. A total of $88.25 \%$ of the predicted genes were assigned and annotated by comparing to the NCBI non-redundant database, KEGG database [16] and InterPro database [17].

\section{Repeat annotation}

The screening of repeat contents from the RepeatMasker [18] analysis based on similarity alignments identified $20.29 \mathrm{Mb}$ in $T$. tridentatus, representing $0.99 \%$ of the genome size. Most of the identified repeat sequences were simple repeats $(0.77 \%)$. To estimate of repeat sequences which are more difficult to detect in the draft

Table 1 Summary of the Tachypleus tridentatus genome assembly and annotation statistic

\begin{tabular}{ll}
\hline $\begin{array}{l}\text { Summary of the Tachypleus tridentatus genome assembly and } \\
\text { annotation statistics. }\end{array}$ \\
\hline $\begin{array}{ll}\text { Tachypleus tridentatus assembly statistics } \\
\text { Assembly size (Gb) }\end{array}$ \\
Number of scaffolds & 143,932 \\
N50 scaffold length (kb) & 165 \\
Largest scaffold (kb) & 5278 \\
Shortest scaffold (kb) & 1 \\
GC content & $32.03 \%$ \\
Average exon length (bp) & 333 \\
Average intron length (bp) & 3792 \\
Tachypleus tridentatus assembly annotation statistics \\
Total number of genes & 24,222 \\
\% BUSCOs & $87.4[10.8], 11.3,1.3$ \\
\hline
\end{tabular}

a of 1066 arthropod BUSCOs Complete [Duplicated], Fragmented, Missing, in the assembly 
assembly, RepeatModeler [19] was used to predict potential existing but unidentified repeats. Based on this analysis, repeat elements totalled $34.83 \%$ in T. tridentatus, including a $13.26 \%$ proportion of transposable elements. Meanwhile, long interspersed elements (LINEs) composed the largest portion at 6.21\%. LTR elements (1.72\%) and DNA elements (5.33\%) were also detected in the $T$. tridentatus genome. To determine the reliability of the repeat contents screening by RepeatMasker and RepeatModeler, we also performed repeat analysis of the L. polyphemus genome for reference. Similar results were obtained with the identification of repeat sequences representing 1.11 and $34.24 \%$ in L. polyphemus, respectively. Given that RepeatMasker use similarity of known repeat sequences in the Repbase database to identify repeats in the input sequence, this suggests that the repeat sequences from horseshoe crabs have a great difference compared with existing homologous repeats.

\section{Assembly assessment}

The completeness of the T. tridentatus genome assembly was assessed using the transcriptome data of the embryonic sample at Stage 21 (the hatch-out stage) of T. tridentatus [20]. It was found that $99.04 \%$ of the transcriptome contigs were aligned to the assembly scaffolds, with an e-value cut-off of $10^{-30}$. To further confirm the completeness of the predicted genes, the commonly used genome assembly validation pipeline BUSCO [21] gene mapping method with 1066 BUSCO Arthropoda gene sets were utilized. The predicted genes of $T$. tridentatus reveals $98.7 \%$ conserved proteins of homologous species with 1052 BUSCOs $(76.6 \%$ complete single-copy BUSCOs, $10.8 \%$ complete duplicated BUSCOs and $11.3 \%$ fragmented BUSCOs). Only $1.3 \%$ of the benchmarked universal single-copy orthologous groups of arthropod genes were missing in the assembly. This demonstrated that most of the evolutionarily conserved core genes were found in T. tridentatus genome, suggesting a remarkable completeness of genome assembly and predicted gene repertoire of $T$. tridentatus.

\section{Phylogeny analysis and divergence time dating}

Two L. polyphemus assemblies have been previously documented [15, 22], one of which was selected to perform comparative genomics according to a relatively higher assembly level. The OrthMCL [23] calculation resulted in a total of 12,116 orthologous groups in the genomes of T. tridentatus and L. polyphemus. Of these, 10, 968 orthologues contained genes found in both horseshoe crab genomes, with 15,905 T. tridentatus and 20, 390 L. polyphemus genes included; moreover, approximately 6880 of the shared genes were single-copy. Functional enrichment analysis showed that these shared genes were involved in several important pathways ( $p$ - value $<0.05$ ), such as metabolic pathways (pyruvate, glycerolipid, amino sugar, nucleotide sugar and so on), ribosome biogenesis and DNA replication. The analysis also identified 1418 protein-coding genes that were only present in T. tridentatus. In total, 1956 genes were specific to L. polyphemus. To place $T$. tridentatus with the most current understanding of the evolution of Chelicerata species, phylogenetic and comparative genomic analyses of $T$. tridentatus and 11 other Chelicerata as well as one Myriapoda outgroup were conducted. The phylogenetic tree was rooted using the centipede $S$. maritima as the outgroup (Fig. 1a). Strong bootstrap support was obtained for spider, mite and tick clades, forming a monophyletic group. T. tridentatus and L. polyphemus were grouped together, forming the Xiphosura clade. The comparative genomic analysis of the 14 species revealed 14,479 orthologous groups containing genes in at least two different species, among which 1993 shared groups were commonly distributed in all sampled species, with 111 single-copy orthologues (Fig. 1b). The single-copy genes enriched for KEGG pathways such as ribosome, oxidative phosphorylation, proteasome, metabolic pathways, and carbon metabolism. Additionally, $T$. tridentatus and L. polyphemus had the most orthologues shared among these two species (2720 (22.2\%) and 2648 $(21.5 \%))$. Pathway enrichment of these genes showed significant enrichment $(p$-value <0.01) for neuroactive ligand-receptor interaction, FoxO signalling pathway and AGE-RAGE signalling pathway in diabetic complications. The latter two KEGG pathways include the important JAK-STAT signalling pathway genes related to innate immunity in arthropods. With respect to speciesspecific genes, 1124 genes were unique to $T$. tridentatus. C. sculpturatus had the most (7328) expanded speciesunique genes, followed by $6247 \mathrm{~N}$. clavipes-specific gene families. In contrast, only 161 genes were unique to $T$. mercedesae. The numbers of species-specific genes in $T$. tridentatus and L. polyphemus were in between, with 1124 and 857, respectively. Nevertheless, considering the fragmentation of the draft genome, there may be unidentified coding genes in the analysed genomes. The species-specific genes described here only refer to the results based on the draft genomes.

The divergence time estimate results for the 7 Chelicerata species showed that the last common ancestor of Asian horseshoe crabs (including T. tridentatus) and L. polyphemus was dated to 130 Mya (121-141) and that the split of the Asian horseshoe crabs $T$. tridentatus and $C$. rotundicauda was dated to 63 Mya (Fig. 2), while the internal split of T. tridentatus from southern coastal China to the Korean Peninsula was dated to 12 Mya. Both the species tree and time tree suggested that horseshoe crabs are closely related to scorpions and that the split of scorpions from horseshoe crabs was dated to 440 Mya (412-468). 


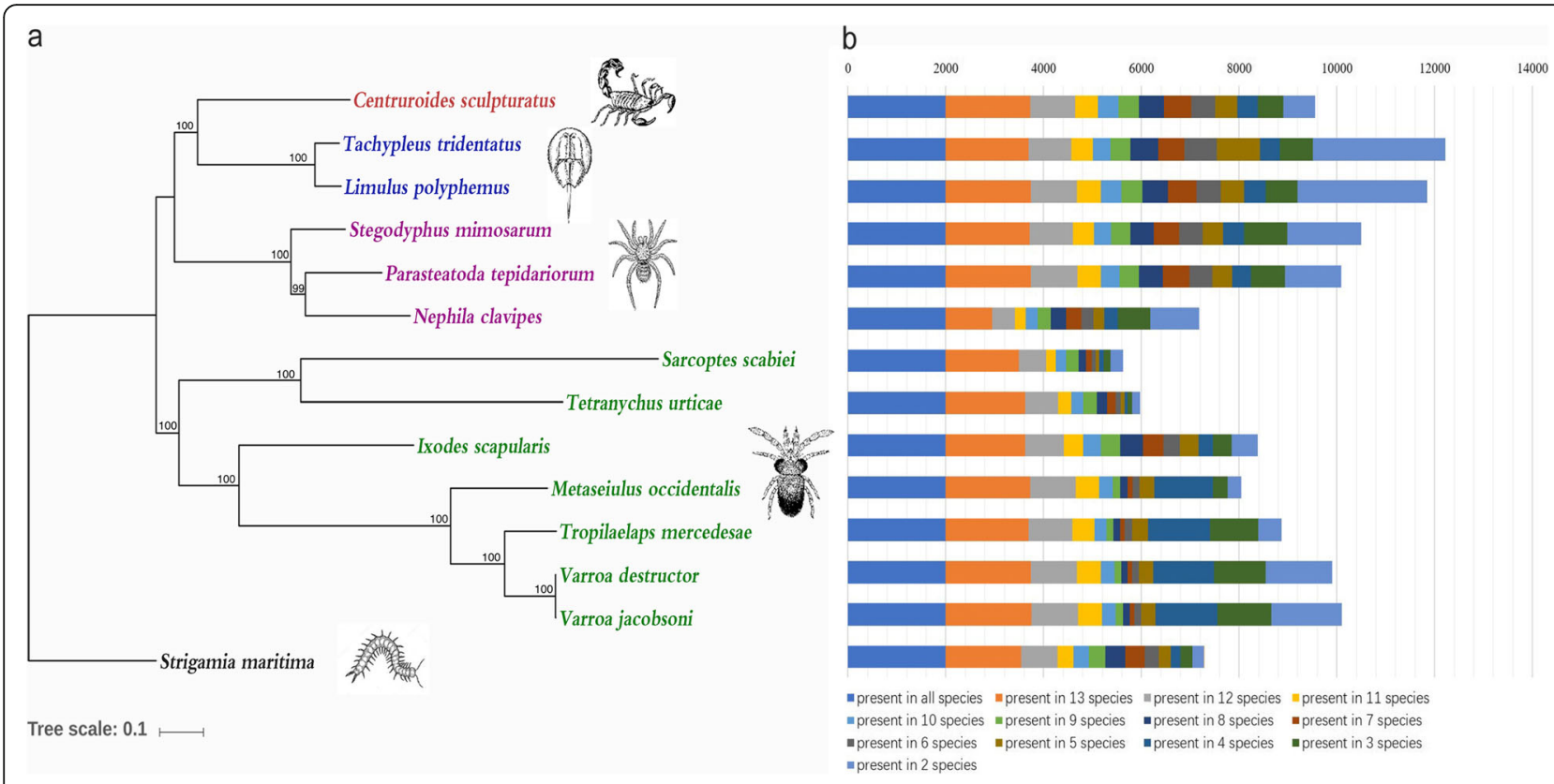

Fig. 1 Comparative genomics. a Phylogenetic placement among T. tridentatus and other Chelicerata species. The phylogeny with 111 single-copy orthologous genes presented in all 14 species was built using RAxML. The tree was rooted with S. maritima. $\mathbf{b}$ Orthology comparsion among T. tridentatus and other Chelicerata species. There were 2720 (22.2\%) and 2648 (21.5\%) orthologs of T. tridentatus and L. polyphemus uniquely shared by the two species (major part of the corresponding light blue bar). C. sculpturatus had the most expanded species unique genes (7328), followed with $6247 \mathrm{~N}$. clavipes specific genes. The number of species specific genes of T. tridentatus and L. polyphemus were in between with 1124 and 857, respectively. The images depicted in Figure 1 were redrawn by the authors according to picture source materials searched from Google images

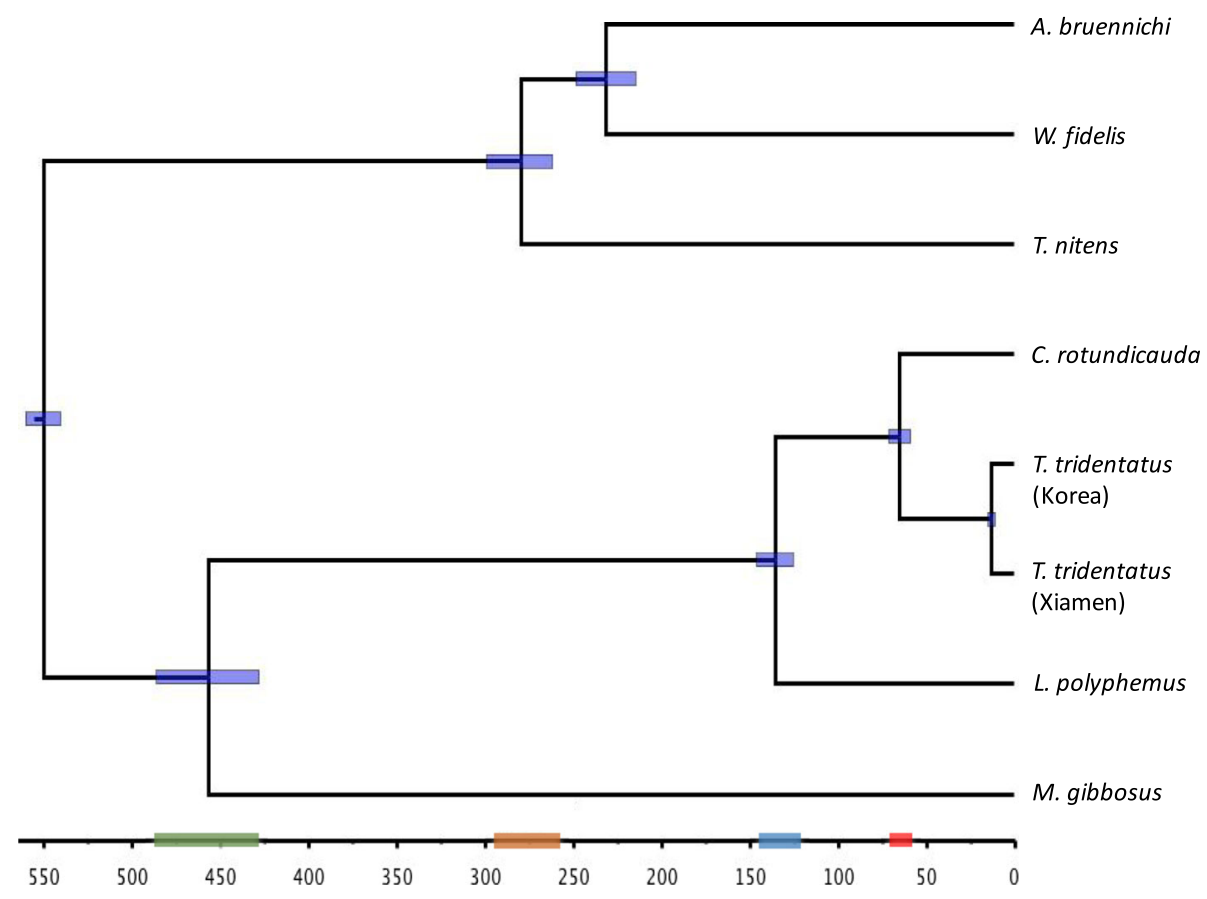

Fig. 2 Bayesian maximum-clade-credibility tree based on the concatenated mitochondrial coding genes dataset in BEAST 2.5.1 with a strict clock, showing the estimated divergence time of Chelicerata species. Node shows the mean estimated divergence times in million years ago (MYA). Purple bars indicate 95\% confidence levels. On the time axis, the green bar shows the divergence time for split of the scorpion from horseshoe crabs; the brown bar shows the inner split time of the three spiders; the blue bar shows the origin of the the last common ancestor of Asian horseshoe crabs (including T. tridentatus) and L. polyphemus; the red bar shows the inner split of C. rotundicauda and T. tridentatus 


\section{Two Hox gene clusters}

Hox genes, which are a highly conserved subclass of homeobox super-class genes that have been extensively investigated, are usually distributed in clusters [34, 35]. Analysis of the Hox gene family showed that the T. tridentatus assembly contained 46 Hox genes, while 43 Hox genes were identified in L. polyphemus (Additional file 1: Table S1). This is the most complete set of Hox genes we obtained based on homeobox domains from these two horseshoe crab assemblies. We found that most Hox genes had at least two representatives in both genomes, which was consistent with a previous whole-genome duplication study in horseshoe crabs [36].

We further examined the positions of the identified Hox genes in the two genomes and found two clusters of adjacently distributed Hox 1 and Hox 4 in the T. tridentatus assembly. In L. polyphemus, there was one Hox cluster of adjacent Hox1 and Hox4 genes and one additional Hox1, Hox2 and Hox3 cluster. Other clusters, such as adjacent Hox 2 and Hox3 clusters and longer clusters of Hox4, Hox7, Ubx, AbdA and AbdB genes found in the two assemblies, could probably be connected to the two clusters mentioned above. Based on the Hox gene positions in the assemblies, our analysis is consistent with a previous study and suggests that there are possibly two Hox gene clusters present in horseshoe crabs if Hox genes are linearly arranged in clusters along the anterior-posterior axis similar to the ancestral arthropod Drosophila [37].

\section{Expansion of crucial gene families of the innate immune signalling pathways in $T$. tridentatus and L. polyphemus}

Immune-related genes can be broadly classified into pattern recognition receptors (PRRs), signaling transduction pathways and effectors. We manually searched the T. tridentatus and L. polyphemus genomes and T. tridentatus transcriptome for homologues of essential immunerelated genes. PRRs in T. tridentatus and L. polyphemus show large amounts of expansion, and key genes in the signal transduction pathways also exhibit a certain degree of expansion (Fig. 3). We examined six PRR families in $T$. tridentatus and L. polyphemus, which included the peptidoglycan recognition proteins (PGRPs), thioestercontaining proteins (TEPs), fibrinogen-related proteins (FREPs), down syndrome cell adhesion molecules (Dscams), galectins and C-type lectins (CTLs). The results revealed 42 FREPs and 117 Dscams in T. tridentatus that were extensively present in both horseshoe crab genomes with functional domains.

Recognition of PAMPs by PRRs triggers signal transduction pathways through transcriptional activation. All known gene family components that play important roles in innate immune signal transduction in arthropods (such as the Toll, IMD, JAK-STAT, and JNK pathways) [39-41] are present in the genomes of T. tridentatus and L. polyphemus. We found that IMD and JAK-STAT pathway genes in T. tridentatus and L. polyphemus exhibited a certain degree of expansion. The orthologue analysis for shared genes in horseshoe crabs with their close evolutionary related species showed that horseshoe crabs have the most unique (more than twenty percent) uniquely shared gene orthologues, including the abovementioned expanded gene families.

Regarding the IMD signalling pathway, imd and IKK exit as a single gene, and we discovered multiple copies of genes encoding death-related ced-3/Nedd2-like proteins (Dredds), MAPKKK transforming growth factor - $\beta$ (TGF $\beta)$ - activated kinase 1 (Tak1) and Relish proteins within T. tridentatus and L. polyphemus. For Dredds, the phylogeny tree shows one branch including 7 corresponding genes identified in the two horseshoe crabs and 1 gene in C. sculpturatus. Another branch encompasses 2 genes in P. tepidariorum (Fig. 4a). The Dredds are required for Tak1 activation. For Tak1, one branch consisting of two gene copies in $T$. tridentatus and $L$. polyphemus suggested gene expansion (Fig. 4b). Moreover, main components of the JAK-STAT signalling pathway, including the receptor Domeless and the Janus Kinase and STAT transcription factor, were identified in both $T$. tridentatus and $L$. polyphemus, indicating that the JAK-STAT pathway has remained intact in horseshoe crabs. Two STAT homologue candidates were identified in the $T$. tridentatus genome with the typical functional domains, including a DNA binding domain and an $\mathrm{SH} 2$ domain which are conserved compared to those reported in insects and shrimps [42]. Plausible homologs of major components of the JNK signalling were also identified in both $T$. tridentatus and L. polyphemus. Phylogenetic analysis of JNKs showed that there were three branches consisting of a pair of corresponding genes identified in the $T$. tridentatus and $L$. polyphemus genomes and one branch formed by a pair of genes in $C$. sculpturatus and S. mimosarum (Fig. 4c).

\section{Antimicrobial peptide diversity in $T$. tridentatus}

A hallmark of the $T$. tridentatus host defence system is the production of antimicrobial peptides, which act as innate immune effectors [43]. We searched the T. tridentatus genome for antimicrobial peptide genes and identified most of the antibacterial peptides that have been reported, including one anti-LPS, two tachyplesin and two big defensin peptides (Fig. 3).

The anti-LPS gene found in the $T$. tridentatus genome contains an antimicrobial peptide (AMP) region between G23 to R83 with two conserved cysteine residues as well as a hydrophobic $\mathrm{NH}^{2}$-terminal and cationic residues clustered in its disulphide loop, which are supposed to act as an affinity site in combination with LPS [44, 45]. 


\begin{tabular}{|c|c|c|c|c|c|}
\hline & $\begin{array}{l}\text { T. tridentatus } \\
\text { (genome) }\end{array}$ & $\begin{array}{l}\text { T. tridentatus } \\
\text { (transcriptom) }\end{array}$ & L. polyphemus & S. maritima & D. melanogaster \\
\hline \multicolumn{6}{|c|}{ Pattern recognition receptors } \\
\hline PGRP & 2 & 2 & 2 & 16 & 13 \\
\hline TEP like & 23 & 2 & 24 & 4 & 6 \\
\hline FREP like & 42 & 32 & 46 & 13 & 13 \\
\hline Dscam like & 117 & 57 & 118 & 1 & 4 \\
\hline Galectin & 5 & 2 & 5 & - & - \\
\hline CTL & 27 & 25 & 27 & - & - \\
\hline \multicolumn{6}{|c|}{ Signaling and Transduction } \\
\hline \multicolumn{6}{|l|}{ Toll pathway } \\
\hline Toll like & 18 & 8 & 17 & 36 & 9 \\
\hline spz like & 8 & 2 & 13 & 1 & 6 \\
\hline Myd88 & 1 & 1 & 1 & 1 & 1 \\
\hline tube & 1 & 1 & 1 & 0 & 1 \\
\hline pelle & 3 & 1 & 1 & 1 & 1 \\
\hline cactus & 1 & 1 & 1 & 1 & 1 \\
\hline dorsal & 1 & 1 & 2 & 1 & 1 \\
\hline TRAF2 & 8 & 8 & 6 & - & - \\
\hline \multicolumn{6}{|l|}{ IMD pathway } \\
\hline imd & 1 & 1 & 1 & $\sim 1$ & 1 \\
\hline Dredd & 4 & 4 & 3 & 1 & 1 \\
\hline Tak1 & 3 & 3 & 3 & 1 & 1 \\
\hline Relish & 6 & 6 & 4 & 2 & 1 \\
\hline IKK & 1 & 1 & 1 & - & - \\
\hline \multicolumn{6}{|l|}{ Other } \\
\hline domeless & 5 & 4 & 5 & 1 & 1 \\
\hline Jak (hop) & 1 & 0 & 1 & 1 & 1 \\
\hline Stat92E & 2 & 2 & 2 & 1 & 1 \\
\hline JNK (bsk) & 3 & 3 & 3 & 1 & 1 \\
\hline Hem & 1 & 1 & 1 & 1 & 1 \\
\hline \multicolumn{6}{|l|}{ Effectors } \\
\hline Anti-LPS factor & 1 & - & $\sim 1$ & - & - \\
\hline Tachyplesin & 2 & - & - & - & - \\
\hline Big defensin & 2 & - & - & - & - \\
\hline
\end{tabular}

Fig. 3 (See legend on next page.) 
(See figure on previous page.)

Fig. 3 Presence of immune related gene families in T. tridentatus and L. polyphemus. Counts of immune related genes are shown for T. tridentatus, $L$. polyphemus, S. maritima [38] and D. melanogaster. The gene number counts according to results of BLASTP search in NR database and InterPro protein domain search from the genome of T. tridentatus and L. polyphemus and the transcriptome of T. tridentatus. Abbreviations: PGRP, peptidoglycan recognition protein; TEP, thioester-containing protein; FREP, fibrinogen-related protein; CTL, C-type lectin

The tachyplesin family includes constitutively expressed cationic peptides comprised of 17-18 amino acids that strongly inhibit the growth of both Gram-negative and -positive bacteria, including pathogenic microorganisms from marine bivalves such as Bonamia ostreae, Perkinsus marinus and Vibrio P1, and can also have strong inhibitory effects on the growth of fungi $[46,47]$. In this study, we identified two tachyplesin precursors in T. tridentatus, each of which consists of 77 amino acids encompassing a putative signal peptide sequence, a mature tachyplesin peptide sequence, a C-terminal arginine followed by the amidation signal residues Gly-Lys-Arg and a 22-aa peptide in the C-terminal portion [47]. In addition to this, two big defensin protein precursors are also present in the $T$. tridentatus genome, one of which is 118 amino acids in length and contains a hydrophobic $\mathrm{N}$-terminal half and a cationic C-terminal half, which may be closely related to its biological activity for broad antimicrobial properties [48].

\section{Intact coagulation cascades in T. tridentatus}

Serine protease-dependent rapid coagulation in horseshoe crabs has been shown to play a key role upon the activation of immune pathways in response to pathogen detection [49]. We found that T. tridentatus and L. polyphemus have all the coagulation-related genes while other related species lack a part of the coagulation pathway (Table 2), indicating a wider diversity of coagulation factors and a relatively intact coagulation cascade present in horseshoe crabs. Factor G, a heterodimer that is specifically activated by the fungal cell wall component $1,3-\beta$-D-glucan, is a special serine protease precursor that provides another starting point for the clotting reaction $[50,51]$. We identified 4 factor $G$ sequences in our T. tridentatus genome and transcriptome assembly, including genes encoding the alpha and beta subunits, respectively. However, we failed to identify any clotting factor $\mathrm{G}$ homologues in other Chelicerata species.

\section{Discussion}

The draft genome of $T$. tridentatus can provide the Chelicerata clade another high-quality publicly available sequence, and would provide an important source for eliminating the uncertainty associated with the evolution of Chelicerata. To date, two papers describing the T. tridentatus genome have been published, revealing $2.16 \mathrm{~Gb}$ and $1.94 \mathrm{~Gb} T$. tridentatus genomes, providing valuable genomic and transcriptomic resources for future studies to exploit horseshoe crabs $[52,53]$. Using a parallel experiment, the assembly size in this study was between the two previous $T$. tridentatus assemblies. Besides, the number of protein-coding genes predicted in T. tridentatus genome was lower that that from the other two published T. tridentatus genomes $(34,966$ and 25,252$)$ but higher than that from $L$. polyphemus $(23,287)$ [18-20]. Considering that previous phylogenetic studies only used transcriptomic data with multiple representations of one gene or obtained low bootstrap support for Arachnida, our phylogenetic tree using 111 single-copy orthologous groups of 13 Chelicerata species and 1 outgroup does not support the hypothesis that Euchelicerata are composed of two parallel groups, the Xiphosura and the Arachnida. Even so, the relatively wider species sampling range and more comprehensive information of this study would be helpful to explore the Chelicerata taxa. We further investigated the divergence time using mitochondrial coding sequences from 7 Chelicerata species, and our analyses suggest that the diversification of the Limulidae and T. tridentatus lineages was congruent approximately 121-141 Mya, and the lineages of the two Asian horseshoe crabs $T$. tridentatus and $C$. rotundicauda was also congruent approximately 57-69 Mya. According to the continental drift theory, before the Triassic Period, virtually all continents were joined to form the supercontinent Pangea, with the breakup of Pangea commencing in the Triassic Period [54]. Approximately 170-120 million years ago (MYA), Pangea broke up into the following two supercontinents: Laurasia and Gondwana [55]. The subsequent lineage divergence within reptiles [56], amphibians [57, 58], mammals [59] and even plants [60] matches the separation and fragmentation of Laurasia and Gondwana. Laurasia fragmented during the mid-Mesozoic Era [61], but until late-Cretaceous Period, the Eurasian and North American plates were still joined together [62]. The ancestor of horseshoe crabs (or their progenitor species) likely originated in the Mesozoic waters of Europe [63, 64]. After the final breakup of the Eurasian and North American plates, the European land mass formed as the shallow seas disappeared and the ancestors of the horseshoe crab migrated. One group migrated to the west along the east coast of North America from Maine to south Florida and from the Gulf of Mexico to the Yucatan Peninsula and evolved into the Atlantic species $L$. polyphemus. The second group migrated to the east through the Tethys, is found along Asia from Japan to India, and evolved into $T$. tridentatus, $T$. gigas, and $C$. 


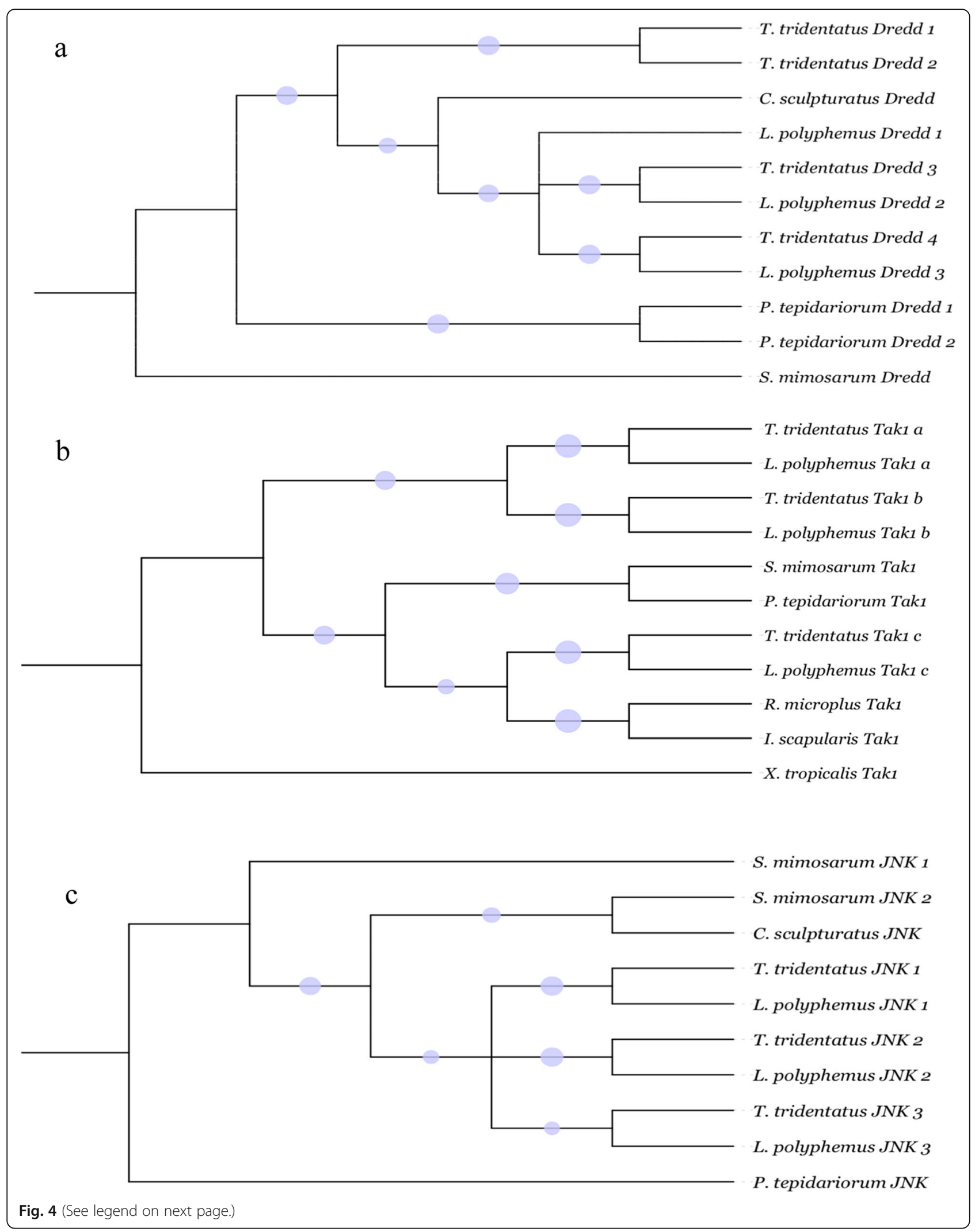


(See figure on previous page.)

Fig. 4 Phylogenetic analysis of immune signaling pathway related genes. a Phylogeny of Dredd genes involved in IMD signaling pathways among multiple Chelicerata species. b Phylogeny of Tak1 genes involved in IMD signaling pathways among multiple Chelicerata species. c Phylogeny of JNK genes involved in JNK signaling pathways among multiple Chelicerata species. The two Neighbor-Joining and one Maximum Likelihood trees were constructed using MEGA with 1000 bootstrap, and rooted with S. mimosarum for Dredds, X. tropicalis for Tak1 and P. tepidariorum for JNKs

rotundicauda. There is evidence showing that the IndiaAsia collision was underway in northern Pakistan ca. 5655 Mya [65]. The diversity of the Asian horseshoe crabs $T$. tridentatus and C. rotundicauda may be related to the India-Asia collision.

Hox genes have been well studied to play essential roles in determining the anterior-posterior axis as well as organogenesis during embryonic development [24, 25]. Research focused on Hox genes suggests the duplication of clusters from one common ancestor [26]. Examination of Hox cluster genes with detailed scaffold positions in the $T$. tridentatus and $L$. polyphemus genomes in this study revealed two Hox gene clusters, suggesting that one round of whole-genome duplication occurred in T. tridentatus and L. polyphemus. Considering that draft genome data was utilized, the identification and scaffold positions in the Hox genes analysis in both horseshoe crab genomes probably provide a minimum estimate. More intact Hox clusters may be recovered with more complete assemblies; thus, we can assume that at least one round of whole-genome duplication occurred in both $T$. tridentatus and $L$. polyphemus.

Horseshoe crabs are an independent ancient group with distributions in Southeast Asia and North America. There must be inherent reasons for their survival against complicated marine environmental changes. Some clues could be found from the comparison of the previously determined L. polyphemus genomes and our presented T. tridentatus genome. Among them, the immune system undoubtedly provides an important guarantee. We searched the two horseshoe crab genomes to investigate the molecular basis of immune signalling pathways, which affect the specificity of foreign pathogen recognition and performance for releasing immune response substances. Genes that are not found in the T. tridentatus genome were supplemented by transcriptome data to restore as accurate of numbers as possible. Although the draft genome is incomplete, the gene count errors should be small enough for the predicted genes according to the BUSCO evaluation results of $98.7 \%$ conserved homologous proteins. From the results we have obtained, the two horseshoe crabs showed high sequence homology for most immune signaling-related gene families, which have been studied previously in other arthropods. Homologs of the FREP and Dscam families play an important role, and pattern recognition receptors with their corresponding functional domains were extensively present in the two horseshoe crab genomes. The Dscam family in arthropods has evolved to recognize a variety of pathogens, and this is supported by the abundant receptor diversity due to alternative splicing of hypervariable regions [27-30]. The abundantly expressed PRRs in the $T$. tridentatus transcriptome suggest an effective ability to recognize a broad range of pathogens, which may be inducted to cope with a great diversity of invading microorganisms in the marine environment. Pathogen recognition would further lead to the activation of signal transduction and the amplification of immune responses, thus producing immune factors that are resistant to microbial activity. Several gene family members in the IMD and JAK-STAT signalling transduction pathway exhibit a certain degree of expansion in T. tridentatus and L. polyphemus. Research in Drosophila has shown that the IMD pathway preferentially recognizes the peptidoglycan molecules present on the surface of Gram-negative bacteria through peptidoglycan recognition receptors (PGRPs), leading to the generation of specific AMPs. The JAKSTAT pathway in arthropods, which is analogous to a cytokine-signalling pathway in mammals, has been implicated as having defence abilities against viral, bacterial or protozoan pathogens [31-33]. The expanded PRRs and signalling pathways might predict that the innate

Table 2 Coagulation Cascade genes in 2 horseshoe crabs, 1 scorpione, and 3 spiders

\begin{tabular}{|c|c|c|c|c|c|c|}
\hline \multirow[b]{2}{*}{ Species } & \multicolumn{2}{|c|}{ Horseshoe Crabs } & \multirow{2}{*}{$\begin{array}{l}\text { Scorpiones } \\
\text { C. sculpturatus }\end{array}$} & \multicolumn{2}{|l|}{ Spiders } & \multirow[b]{2}{*}{ P. tepidariorum } \\
\hline & T. tridentatus & L. polyphemus & & N. clavipes & S. mimosarum & \\
\hline Factor C & 2 & 4 & 5 & 4 & 6 & 4 \\
\hline Factor B & 10 & 12 & 8 & 4 & 7 & 7 \\
\hline Factor G & 4 & $1^{a}$ & 0 & 0 & 0 & 0 \\
\hline Proclotting Enzyme & 9 & 11 & 7 & 5 & 5 & 5 \\
\hline Coagulogen & 6 & 6 & 0 & 0 & 0 & 0 \\
\hline Total & 30 & 33 & 20 & 13 & 18 & 16 \\
\hline
\end{tabular}

Identified in previous study 
immunity of T. tridentatus has strong signal reception and lineage-specific signal transduction abilities. The interactions among the components in T. tridentatus should be paid more attention.

The generation of AMPs is an important aspect of immune responses in horseshoe crabs. The transcription of specific AMPs, which act as important innate immune effectors, are activated through the Toll, IMD, JAKSTAT or JNK pathway based on the recognition of bacteria, fungi, viruses or parasites. We identified most of the antimicrobial peptides isolated in previous studies in T. tridentatus assembly, including anti-LPS, tachyplesin, and big defensin peptides. However, in the L. polyphemus genome, we failed to find any of the tachyplesin family genes, probably because these antimicrobial peptides are usually shorter and have a high degree of species specificity. There is increasing evidence that AMPs in horseshoe crabs not only possess broad-spectrum antimicrobial capabilities but also have a strong resistibility to enveloped viruses, parasites and tumour cells [66-69]. Moreover, antimicrobial peptide counterparts in horseshoe crab haemolymph have also been identified in other evolutionarily conserved animal population representatives [70-72]. Thus, more work needs to be undertaken to study the specific function of the AMPs in T. tridentatus.

Serine protease-dependent haemolymph coagulation is a major component of the innate immune system in horseshoe crabs. Activation of the horseshoe crab coagulation cascade consists of four coagulation factors including factor $\mathrm{C}$, factor $\mathrm{B}$, factor $\mathrm{G}$ and proclotting enzyme [73, 74]. Factor $C$ and factor $G$ are two serine protease zymogens that act as biosensors and can be activated by LPS or $(1 \rightarrow 3)-\beta$-D-glucan, which are major components of the cell walls of Gram-negative bacteria and fungi, respectively. We found relatively high number of genes for all four coagulation factors in the T. tridentatus assembly, indicating a complete coagulation cascade in horseshoe crabs. Other Chelicerata species can lack factor G and coagulogen. This might be because of a limited annotation of the draft genome assemblies or there might be other special biosensors involved in their antifungal recognition process. Although the more direct internal cause for the long-term evolutionary conservation and success of horseshoe crabs with abilities to maintain morphological stability in a fluctuating marine environment may be the combination of a wide feeding spectrum, substantial saline tolerance and insensitivity to temperature by horseshoe crabs $[75,76]$, there is a presumption that the haemolymph of horseshoe crabs may improve their adaptive strategies and increase their population survival rate $[77,78]$.

\section{Conclusions}

Our draft assembly of $T$. tridentatus was sequenced into a $2.06 \mathrm{~Gb}$ of genome consisting of 143,932 scaffolds with an N50 scaffold size of $165 \mathrm{~kb}$. In total, 24,222 proteincoding genes were conservatively predicted as present in the $T$. tridentatus genome, revealing $98.7 \%$ completeness with 1052 BUSCOs.

Further analysis of the T. tridentatus genome included phylogeny analysis and divergence time dating using newly published Chelicerata species, as well as selective analysis of Hox genes, innate immunity-related genes, coagulation factors and antimicrobial peptides. We found that the two horseshoe crabs $T$. tridentatus and $L$. polyphemus had the most orthologues shared among two species, and were enriched for the immune-related JAK-STAT signalling pathway. Furthermore, two clusters of Hox genes were predicted in both assemblies, suggesting that at least one round of whole-genome duplication occurred in both T. tridentatus and L. polyphemus. The innate immunity gene investigation showed that conserved pattern recognition receptor gene families and several signal transduction pathway genes involved in IMD and JAK-STAT exhibit a certain degree of expansion in both horseshoe crab genomes. Moreover, all of the antibacterial peptides reported in previous studies, as well as their effective antimicrobial sites, have also been identified in the T. tridentatus genome. Beyond that, according to our analysis, intact coagulation cascade-related genes were identified in the T. tridentatus genome, with high numbers of total gene counts. Apart from the abovementioned results, there may remain other aspects of horseshoe crabs that may be greatly conducive to their adaptive advantages in marine environments through their long evolutionary history that need to be studied further and established in future studies.

\section{Methods \\ T. tridentatus specimens and DNA extraction}

T. tridentatus is endangered according to the Red List (https://www.iucnredlist.org/species/21309/149768986).

The use of the $T$. tridentatus species collected in this study was to separate $0.1 \mathrm{~g}$ leg skeleton muscle tissue for DNA extraction. This study was reviewed and approved by the Animal Care and Use Committee of Minjiang University. All the required collection and permits had been obtained before any work was started. Only one $T$. tridentatus was purchased in the aquatic market in Xiamen, Fujian Province, China and was released after $0.1 \mathrm{~g}$ leg muscle collection. Total genomic DNA was extracted using an E.Z.N.A. Insect DNA Extraction Kit (Omega Bio-Tek, Inc., Norcross, GA, USA) at the State Key Laboratory of Genetic Engineering in Fudan University, Shanghai, China. The genomic research about $T$. 
tridentatus covers the evolution history of this endangered species, and may reveal genomic characteristics that limit their survival, which could provide a basis for the species protection.

\section{Genome sequencing and assembly}

The Illumina TruSeq Nano DNA Library Prep Kit (Illumina, San Diego, CA) was used to construct the 400-bp and 800-bp paired-end sequencing libraries. Long matepair libraries featuring 3-kb inserts were prepared using a CHGC kit (CHGC, China). The Nextera MP Sample Prep Kit (Illumina, San Diego, CA) was used to build long mate-pair libraries with 8 - and $12-\mathrm{kb}$ insert sizes. Wholegenome sequencing was performed on the Illumina HiSeq 2500 and HiSeq X Ten platforms generating 250-bp and 150-bp paired-end reads, respectively. Five libraries of nominal insert sizes, including 400 bp, 800 bp, 3- kb, 8- kb and $12-\mathrm{kb}$, were sequenced at expected genome coverages of $60 \times, 30 \times, 7 \times, 7 \times$ and $20 \times$, respectively. The generated clean reads from the $400 \mathrm{bp}, 800 \mathrm{bp}$ and $3-\mathrm{kb}$ insert size libraries were used for the estimation of the genome size via JELLYFISH v1.116 [79] with a k-mer length of 17. The genome size of $T$. tridentatus was estimated using online scripts (https://github.com/josephryan/estimate_genome_ size.pl) from a k-mer distribution generated by jellyfish. Contigs were assembled using Velvet [80] by cutting the short reads into k-mers and establishing the de Bruijn table to correct and complete the contigs, which were further scaffolded and gap-filled using SSPACE-STANDARD [81] with long mate-pair reads (8- and 12-kb).

\section{Automated annotation}

T. tridentatus genome assembly automatic gene prediction was established using AUGUSTUS (Version 3.3) [82]. The predicted genes were annotated by comparing to the NCBI non-redundant database (NR), Kyoto Encyclopedia of Genes and Genomes (KEGG) database [16] and InterPro database [17] with an E-value threshold of $10^{-5}$. The three annotation results were combined as the annotation of the predicted genes. The benchmarking sets of universal single-copy orthologues (BUSCOs) [21] were used to assess the completeness of the predicted genes with 1066 Arthropoda datasets. The repeat contents of $T$. tridentatus and $L$. polyphemus were first analysed using RepeatMasker (version open-4.0.5) [18] with merostomata as the query species and running with rmBLASTn (version 2.2.27+) [83] and RepBase (version 20,140,131) [84]. RepeatModeler (version open1.0.11) [19] was used to build the repeat database, which was further masked by RepeatMasker.

\section{Transcriptome analysis}

RNA-seq raw data obtained from the embryonic sample at Stage 21 (the hatch-out stage) of $T$. tridentatus were downloaded from the NCBI SRA database (accession number SRX330201) [20]. De novo assembly of the transcriptome was performed with Trinity [85] with default parameters. Protein-coding sequences and the longest transcript ORFs were predicted via Transdecoder [85].

\section{Orthology and phylogeny analysis}

The published genome assembly, coding sequences and protein sequences for the Atlantic horseshoe crab $L$. polyphemus submitted by Washington University were downloaded from NCBI with RefSeq ID 2304488, accession GCF_000517525.1. The non-redundant protein sequences in $L$. polyphemus were selected by sorting the protein scaffold positions and filtering out overlapped proteins. Protein sequences of other 11 Chelicerata species, including three Araneae (Nephila clavipes, Parasteatoda tepidariorum, and Stegodyphus mimosarum), seven Acari (Varroa jacobsoni, Tropilaelaps mercedesae, Sarcoptes scabiei, Metaseiulus occidentalis, Tetranychus urticae, Varroa destructor, and Ixodes scapularis), and one scorpion (Centruroides sculpturatus) were downloaded from the GenBank database. Additional outgroup protein sequences from the centipede Strigamia maritima were downloaded from the UniProt database. OrthoMCL [23] was used to perform orthologous gene family clustering and provide calculation results for the number of genes in each orthologous group. Selected single copy orthologues were subjected to multiple sequence alignments using ClustalW v2.0.12 [86] and Maximum Likelihood phylogenetic trees were built using the PROTGAMMAWAG model with 1000 bootstraps implemented in RAxML v8.2.12 [87], with centipede as an out-group. The KOBAS 3.0 web server [88-90] was used for the functional gene set enrichment of shared and species-specific genes from $L$. polyphemus and $T$. tridentatus and the single-copy gene set for the 13 Chelicerata species and centipede with the KEGG database [16].

\section{Divergence time estimates}

Thirteen intact mitochondrial coding sequences of 7 species were downloaded from the NCBI gene database and used to build the time tree containing three horseshoe crabs (Tachypleus tridentatus, Carcinoscorpius rotundicauda and Limulus polyphemus), one scorpion (Mesobuthus gibbosus) and three Araneae (Argiope bruennichi, Wadicosa fidelis and Tetragnatha nitens). The 13 mitochondrial coding sequences for T. tridentatus collected in Korea were used to query for identical genes in our $T$. tridentatus genome and transcriptome assembly using blastn (blast, Basic Local Alignment Search Tool). Alignment of sequences with identities of at least $97 \%$ was considered to be the counterparts of mitochondrial coding sequences in $T$. tridentatus 
identified in this study. Multiple sequence alignments of concatenated mitochondrial coding sequences of 7 species were processed using ClustalW v2.0.12 [86]. BEAUti v2.5.1 [91-93] was used to generate the BEAST input XML files, after which the tree was dated using BEAST v.2.5.1. The Hasegawa-Kishino-Yano (HKY) substitution model with empirical frequencies and a strict clock model were used. Fossil information for all Chelicerata species were used to calibrate the tree with a normal distribution of 530 Mya and standard deviation 5 Mya [94]. A chain length of $6,000,000$ generations was run when sampling every 1000 generations. Software Tracer was used to analyse the BEAST log file output. TreeAnnotator [95] and FigTree were used for tree production and tree visualization, respectively.

\section{Identification of Hox genes, immune pathway genes and coagulation factors}

Protein sequences of Hox genes, essential immune signalling-related genes and coagulation factors of species closely related to horseshoe crabs were downloaded from the NCBI protein database and used as query sequences. Blastp was then used with an e-value of $10^{-15}$ to search for homologues using the T. tridentatus and $L$. polyphemus genomes as databases. Tblastn was used with an e-value of $10^{-15}$ to search for corresponding transcripts in the $T$. tridentatus transcriptome. Transcripts found in the transcriptome were further compared to the genome of $T$. tridentatus by blastn with an e-value of $10^{-5}$ to complement identified genes and to reduce the data omission in the genome. Putative genes were selected based on positive scores and alignment length percentages defined by dividing the alignment length by query length, and then filtrated according to their annotation in the NCBI non-redundant database (NR) and InterPro database [17].

\section{Dredd, Tak1 and JNK gene phylogenetic analysis}

MEGA (version 7.0) [96] was used to construct two neighbour-joining trees and a maximum likelihood tree with 1000 bootstraps using putative protein sequences as the default parameters. Domains from all the selected genes annotated as IPR001309, IPR001932 and IPR000719 in the InterPro database were used for multiple alignment. Dredd from Stegodyphus mimosarum, Tak1 from Xenopus tropicalis and JNK from Parasteatoda tepidariorum were chosen as outgroups for the above phylogenetic trees.

\section{Identification of putative antimicrobial peptides}

Because antimicrobial peptides (AMPs) are commonly short in length, display wide variety and have large differences in their structures and functions within species, tblastn was used to identify potential AMPs using the $T$. tridentatus and L. polyphemus genome assemblies as databases. Identified putative AMPs were further used as query sequences to search for corresponding transcripts. The prediction of ORFs was performed using NCBI ORF finder (https://www.ncbi.nlm.nih.gov/orffinder/) and the annotation of those ORFs was performed by blastp with the NR database.

\section{Supplementary information}

Supplementary information accompanies this paper at https://doi.org/10 1186/s12864-020-6488-1.

Additional file1: Table S1. Comparison of homeobox ANTP class genes between $T$. tridentatus and L. polyphemus genome.

\section{Abbreviations}

AbdA: Abdominal-A; AbdB: Abdominal-B; AMP: Antimicrobial Peptide; blast: Basic Local Alignment Search Tool; BUSCO: Benchmarking Universal Single-Copy Orthologs; Dscams: Down Syndrome Cell Adhesion Molecules; FoxO: The Forkhead Box O; FREPs: Fibrinogen-Related Proteins; Hox genes: Homeotic Genes; IMD: Immune deficiency; JAK: Janus kinase; JNK: cJun N-terminal Kinase; KEGG: Kyoto Encyclopedia of Genes and Genomes; LINEs: Long Interspersed Elements; LPS: Lipopolysaccharide; LTR: Long Terminal Repeat; ORF: Open Reading Frame; PAMPs: Pathogen-Associated Molecular Patterns; PRRs: Pattern Recognition Receptors; RAGE: Receptor for Advanced Glycation Endproducts; STAT: Signal Transducer and Activator of Transcription Protein; Ubx: Ultrabithorax

\section{Acknowledgements}

Not applicable.

\section{Authors' contributions}

YZ, MLC and JMC designed the study. MLC, DBC, LWR, YK, HS collected horseshoe crab samples. MLC, YL, QY, and LZ carried out the experiments. $Y Z, Y L, Q Y$ analyzed the data. YZ, MLC, JMC, YL and YK wrote the manuscript. All authors read and approved the final manuscript.

\section{Funding}

This work was supported in part by the Chinese Academy of Sciences (KFJSTS-QYZD-126), the National Key R\&D Program of China (2017YFC1404504), the Major State Basic Research Development Program of China (973 Program) (2015CB755906), Project 2018 N2001 from Department of Fujian Science and Technology and Program for Innovative Research Team in Science and Technology in Fujian Province University, and Beihai Pilot City Program for the National Innovative Development of the Marine Economy (BHSFS002). The funding bodies played no role in the design of the study and collection, analysis, and interpretation of data and in writing the manuscript.

\section{Availability of data and materials}

All data are available from the following databases as described. The raw sequences for T. tridentatus have been deposited in the NCBI SRA: BioProject ID PRJNA510236, BioSample ID SAMN10600682, accession SRX6412182 -

SRX6412188. The whole genome assembly has been deposited at GenBank under the BioProject ID PRJNA510236, accession QCWK00000000. The

version described in this paper is version QCWK01000000. RNA-seq raw data obtained from the embryonic sample at Stage 21 (the hatch-out stage) of $T$. tridentatus were downloaded from the NCBI SRA database (accession number SRX330201). The published genome assembly, coding sequences and protein sequences for the Atlantic horseshoe crab L. polyphemus submitted by Washington University were downloaded from NCBI with RefSeq ID 2304488, accession GCF_000517525.1. Protein sequences of three Araneae (Nephila clavipes, Parasteatoda tepidariorum, and Stegodyphus mimosarum), seven Acari (Varroa jacobsoni, Tropilaelaps mercedesae, Sarcoptes scabiei, Metaseiulus occidentalis, Tetranychus urticae, Varroa destructor, and Ixodes scapularis), and one scorpion (Centruroides sculpturatus) were downloaded from NCBI Genbank with following accession numbers: GCA_002102615.1, GCF_000365465.2, GCA_000611955.2, GCA_002532875.1, GCA_002081605.1, GCA_000828355.1,GCA_000255335.1,GCA_000239435.1, GCA_002443255.1, 
GCA_000208615.1 and GCA_000671375.2. 15,047 protein sequences from the centipede Strigamia maritima were downloaded from UniProt (https://www. uniprot.org/uniprot/?query=Strigamia+maritima\&sort=score). Thirteen intact mitochondrial coding sequences of 7 species were downloaded from the NCBI gene database with following accession numbers: 7768785-7768797 for Tachypleus tridentatus, 14049643-14049655 for Carcinoscorpius rotundicauda, 803775-803787 for Limulus polyphemus, 3183285-3183286, 31832893183291, 3183293, 3183295, 3183297-3183298, 3183300, 3183305, 3183313, 3183315 for Mesobuthus gibbosus, 19591985-19591997 for Argiope bruennichi, 22834025-22834037 for Wadicosa fidelis and 26047144, 26047146-26047148, 26047151, 26047156, 26047158, 26047160, 26047167-26047170, 26047172 for Tetragnatha nitens.

\section{Ethics approval and consent to participate}

The experimental protocol in this study for Tachypleus tridentatus genome sequencing was established according to the Animal Care and Use Committee of Minjiang University and was approved by the Animal ethics committee, Institute of Oceanography, Minjiang University.

\section{Consent for publication}

Not applicable.

\section{Competing interests}

The authors declare that they have no competing interests.

\section{Author details}

'State Key Laboratory of Genetic Engineering, School of Life Sciences, Fudan University, Shanghai 200438, China. ${ }^{2}$ Shanghai-MOST Key Laboratory of Health and Disease Genomics, Chinese National Human Genome Center at Shanghai, Shanghai 201203, China. Institute of Oceanography, Minjiang University, Fuzhou 350108, China. ${ }^{4}$ State Key Laboratory Breeding Base of Marine Genetic Resources, Fujian Collaborative Innovation Center for Exploitation and Utilization of Marine Biological Resources, Third Institute of Oceanography, Ministry of Natural Resources, 184 University Road, Xiamen 361005, China. ${ }^{5}$ Sino-French Hoffmann Institute, School of Basic Medical Sciences, Guangzhou Medical University, Guangzhou 511436, China.

\section{Received: 21 April 2019 Accepted: 13 January 2020}

\section{Published online: 10 February 2020}

\section{References}

1. Rudkin DM, Young GA, Nowlan GS. The oldest horseshoe crab: a new xiphosurid from late Ordovician Konservat-Lagerstätten deposits, Manitoba, Canada. Palaeontology. 2008:51:1-9.

2. Fisher DC. The Xiphosurida: archetypes of bradytely? In: Eldredge N, Stanley SM, editors. Living fossils. New York: Springer; 1984. p. 196-213.

3. Sekiguchi K. Biology of horseshoe crabs. Portland: International Specialized Book Service Incorporated; 1988.

4. Iwanaga S, Kawabata S, Muta T. new types of clotting factors and defense molecules found in horseshoe crab hemolymph: their structures and functions. J Biochem. 1998;123:1-15.

5. Tan NS, Ho B, Ding JL. High-affinity LPS binding domain(s) in recombinant factor $C$ of a horseshoe crab neutralizes LPS-induced lethality. FASEB J. 2000; 14:859-70.

6. Muta T, Iwanaga S. The role of hemolymph coagulation in innate immunity. Curr Opin Immunol. 1996;8:41-7.

7. Nellaiappan K, Sugumaran M. On the presence of prophenoloxidase in the hemolymph of the horseshoe crab, Limulus. Comp Biochem Physiol B: Biochem Mol Biol. 1996:113:163-8.

8. Pieters J. Evasion of host cell defense mechanisms by pathogenic bacteria Curr Opin Immunol. 2001;13:37-44.

9. Akira S, Uematsu S, Takeuchi O. Pathogen recognition and innate immunity. Cell. 2006;124:783-801.

10. Lemaitre B, Hoffmann J. The host defense of Drosophila melanogaster Annu Rev Immunol. 2007;25:697-743

11. Iwanaga $\mathrm{S}$, Lee BL. Recent advances in the innate immunity of invertebrate animals. BMB Rep. 2005;38:128-50.

12. Chipman AD, Ferrier DE, Brena C, Qu J, Hughes DS, Schröder R, et al. The first myriapod genome sequence reveals conservative arthropod gene content and genome organisation in the centipede Strigamia maritima. PLoS Biol. 2014;12:e1002005.
13. Anderson LI, Shuster CN. Throughout geologic time: where have they lived? Cambridge: Harvard University Press; 2003.

14. Faurby S, King TL, Obst M, Hallerman EM, Pertoldi C, Funch P. Population dynamics of American horseshoe crabs - historic climatic events and recent anthropogenic pressures. Mol Ecol. 2010;19:3088-100.

15. Battelle BA, Ryan JF, Kempler KE, Saraf SR, Marten CE, Warren WC, et al. Opsin repertoire and expression patterns in horseshoe crabs: evidence from the genome of Limulus polyphemus (Arthropoda: Chelicerata). Genome Biol Evol. 2016:8:1571-89.

16. KEGG database. https://www.kegg.jp/. Accessed 23 Apr 2018.

17. InterPro database. http://www.ebi.ac.uk/interpro/search/sequence/. Accessed 23 Apr 2018.

18. Tarailo-Graovac M, Chen N. Using RepeatMasker to identify repetitive elements in genomic sequences. Curr Protoc Bioinformatics. 2009;25(4 10):1-4.

19. Smit AF, Hubley R. RepeatModeler Open-1.0; 2008

20. Chen M, Wang C, Wang W, Ji G, Hu B, Du M, et al. De novo assembly and characterization of early embryonic transcriptome of the horseshoe crab Tachypleus tridentatus. PLoS One. 2016:11:e0145825.

21. Simão FA, Waterhouse RM, loannidis P, Kriventseva EV, Zdobnov EM. BUSCO: assessing genome assembly and annotation completeness with single-copy orthologs. Bioinformatics. 2015;31:3210-2.

22. Simpson SD, Ramsdell JS, Watson WH III, Chabot CC. The draft genome and transcriptome of the Atlantic horseshoe crab, Limulus polyphemus. Int J Genomics. 2017;2017:1-14

23. Li L, Stoeckert CJ, Roos DS. OrthoMCL: identification of ortholog groups for eukaryotic genomes. Genome Res. 2003:13:2178-89.

24. Gehring W. Homeotic genes, the homeobox, and the spatial organization of the embryo. Harvey Lect. 1985:81:153-72.

25. Gehring WJ. A history of the homeobox. Guidebook to the Homeobox Genes; 1994. p. 1-10.

26. Garcia-Fernàndez J. The genesis and evolution of homeobox gene clusters. Nat Rev Genet. 2005;6:881.

27. Schmucker D, Clemens JC, Shu H, Worby CA, Xiao J, Muda M, et al. Drosophila Dscam is an axon guidance receptor exhibiting extraordinary molecular diversity. Cell. 2000;101:671-84.

28. Graveley BR, Kaur A, Gunning D, Zipursky SL, Rowen L, Clemens JC. The organization and evolution of the dipteran and hymenopteran Down syndrome cell adhesion molecule (Dscam) genes. RNA. 2004;10:1499-506.

29. Brites D, McTaggart S, Morris K, Anderson J, Thomas K, Colson I, et al. The Dscam homologue of the crustacean Daphnia is diversified by alternative splicing like in insects. Mol Biol Evol. 2008;25:1429-39.

30. Yue Y, Meng Y, Ma H, Hou S, Cao G, Hong W, et al. A large family of Dscam genes with tandemly arrayed 5' cassettes in Chelicerata. Nat Commun. 2016:7:11252.

31. Souza-Neto JA, Sim S, Dimopoulos G. An evolutionary conserved function of the JAK-STAT pathway in anti-dengue defense. Proc Natl Acad Sci. 2009; 106:17841-6.

32. Gupta L, Molina-Cruz A, Kumar S, Rodrigues J, Dixit R, Zamora RE, et al. The STAT pathway mediates late-phase immunity against Plasmodium in the mosquito Anopheles gambiae. Cell Host Microbe. 2009;5:498-507.

33. Liu L, Dai J, Zhao YO, Narasimhan S, Yang Y, Zhang L, et al. Ixodes scapularis JAK-STAT pathway regulates tick antimicrobial peptides, thereby controlling the agent of human granulocytic anaplasmosis. J Infect Dis. 2012;206:1233-41.

34. Holland PW. Evolution of homeobox genes. Wiley Interdiscip Rev Dev Biol. 2013;2:31-45.

35. Ferrier D. When is a Hox gene not a Hox gene? The importance of gene nomenclature. Evolving Pathways: key themes in Evolutionary Developmental Biology. Cambridge: Cambridge University Press; 2008. p. 175-93.

36. Kenny NJ, Chan KW, Nong W, Qu Z, Maeso I, Yip HY, et al. Ancestral wholegenome duplication in the marine chelicerate horseshoe crabs. Heredity. 2016;116:190.

37. Hughes $\mathrm{CL}$, Kaufman TC. Hox genes and the evolution of the arthropod body plan. Evol Dev. 2002;4:459-99.

38. McTaggart SJ, Conlon C, Colbourne JK, Blaxter ML, Little TJ. The components of the Daphnia pulex immune system as revealed by complete genome sequencing. BMC Genomics. 2009;10:175.

39. Tanji T, Ip YT. Regulators of the toll and Imd pathways in the Drosophila innate immune response. Trends Immunol. 2005;26:193-8.

40. Boutros M, Agaisse $H$, Perrimon N. Sequential activation of signaling pathways during innate immune responses in Drosophila. Dev Cell. 2002;3:711-22. 
41. Li F, Xiang J. Signaling pathways regulating innate immune responses in shrimp. Fish Shellfish Immun. 2013;34:973-80.

42. Chen WY, Ho KC, Leu JH, Liu KF, Wang HC, Kou GH, et al. WSSV infection activates STAT in shrimp. Dev Comp Immunol. 2008;32:1142-50.

43. Miyata T, Tokunaga F, Yoneya T, Yoshikawa K, Iwanaga S, Niwa M, et al. Antimicrobial peptides, isolated from horseshoe crab hemocytes, tachyplesin II, and polyphemusins I and II: chemical structures and biological activity. J Biochem. 1989;106:663-8.

44. Aketagawa J, Miyata T, Ohtsubo S, Nakamura T, Morita T, Hayashida H, et al. Primary structure of limulus anticoagulant anti-lipopolysaccharide factor. J Biol Chem. 1986;261:7357-65.

45. Muta T, Miyata T, Tokunaga F, Nakamura T, Iwanaga S. Primary structure of anti-lipopolysaccharide factor from American horseshoe crab, Limulus polyphemus. J Biochem. 1987;101:1321-30

46. Nakamura T, Furunaka H, Miyata T, Tokunaga F, Muta T, Iwanaga S, et al. Tachyplesin, a class of antimicrobial peptide from the hemocytes of the horseshoe crab (Tachypleus tridentatus). Isolation and chemical structure. J Biol Chem. 1988;263:16709-13.

47. Shigenaga T, Muta T, Toh Y, Tokunaga F, Iwanaga S. Antimicrobial tachyplesin peptide precursor. cDNA cloning and cellular localization in the horseshoe crab (Tachypleus tridentatus). J Biol Chem. 1990;265:21350-4.

48. Saito T, Kawabata S, Shigenaga T, Takayenoki Y, Cho J, Nakajima H, et al. A novel big defensin identified in horseshoe crab hemocytes: isolation, amino acid sequence, and antibacterial activity. J Biochem. 1995;117:1131-7.

49. Muta T, Iwanaga S. Clotting and immune defense in Limulidae. Invertebrate Immunology: Springer; 1996. p. 154-89.

50. Morita T, Tanaka S, Nakamura T, Iwanaga S. A new ( $\rightarrow$ 3)- $\beta$-D-glucanmediated coagulation pathway found in limulus amebocytes. FEBS Lett. 1981;129:318-21.

51. Muta T, Seki N, Takaki Y, Hashimoto R, Oda T, Iwanaga A, et al. Purified horseshoe crab factor $G$ reconstruction and characterization of the (1,3)- $\beta$ D-glucan-sensitive serine protease cascade. J Biol Chem. 1995;270:892-7.

52. Gong L, Fan G, Ren Y, Chen Y, Qiu Q, Liu L, et al. Chromosomal level reference genome of Tachypleus tridentatus provides insights into evolution and adaptation of horseshoe crabs. Mol Ecol Resour. 2019;19:744-56.

53. Liao YY, Xu PW, Kwan KY, Ma ZY, Fang HY, Xu JY, et al. Draft genomic and transcriptome resources for marine chelicerate Tachypleus tridentatus. Sci Data. 2019:6:190029.

54. Dietz RS, Holden JC. Reconstruction of Pangaea: breakup and dispersion of continents, Permian to present. J Geophys Res. 1970;75:4939-56.

55. Pyron RA. Biogeographic analysis reveals ancient continental vicariance and recent oceanic dispersal in amphibians. Syst Biol. 2014;63:779-97.

56. Gamble T, Bauer AM, Greenbaum E, Jackman TR. Evidence for Gondwanan vicariance in an ancient clade of gecko lizards. J Biogeogr. 2008;35:88-104

57. Roelants K, Bossuyt F. Archaeobatrachian paraphyly and Pangaean diversification of crown-group frogs. Syst Biol. 2005;54:111-26.

58. San Mauro D, Vences M, Alcobendas M, Zardoya R, Meyer A. Initial diversification of living amphibians predated the breakup of Pangaea. Am Nat. 2005;165:590-9.

59. Springer MS, Murphy WJ, Eizirik E, O'Brien SJ. Placental mammal diversification and the cretaceous-tertiary boundary. Proc Natl Acad Sci. 2003;100:1056-61.

60. Mao K, Milne Rl, Zhang L, Peng Y, Liu J, Thomas P, et al. Distribution of living Cupressaceae reflects the breakup of Pangea. Proc Natl Acad Sci. 2012;109:7793-8.

61. Gardner JD, Nydam RL. Mesozoic and Cenozoic lissamphibian and squamate assemblages of Laurasia_introduction to the special issue. Palaeobiodiversity and Palaeoenvironments. 2013;93:391-5.

62. Wicander R, Monroe JS. Historical geology : evolution of earth and life through time. 4th ed. USA: Brooks/Cole; 2000.

63. Shuster JC. A pictorial review of the natural history and ecology of the horseshoe crab Limulus polyphemus, with reference to other Limulidae. Prog Clin Biol Res. 1982;81:1-52.

64. Briggs DE, Moore RA, Shultz JW, Schweigert G. Mineralization of soft-part anatomy and invading microbes in the horseshoe crab Mesolimulus from the upper Jurassic Lagerstätte of Nusplingen, Germany. Proc R Soc Lond B Biol Sci. 2005;272:627-32

65. Ding L, Qasim M, Jadoon IA, Khan MA, Xu Q, Cai F, et al. The India-Asia collision in North Pakistan: insight from the U-Pb detrital zircon provenance of Cenozoic foreland basin. Earth Planet Sci Lett. 2016;455:49-61.
66. Morvan A, Iwanaga S, Comps M, Bachere E. In vitro activity of the Limulus antimicrobial peptide tachyplesin I on marine nivalve pathogens. J Invertebr Pathol. 1997;69:177-82

67. Morimoto M, Mori H, Otake T, Ueba N, Kunita N, Niwa M, et al. Inhibitory effect of tachyplesin I on the proliferation of human immunodeficiency virus in vitro. Chemotherapy. 1991;37:206-11.

68. Murakami T, Niwa M, Tokunaga F, Miyata T, Iwanaga S. Direct virus inactivation of tachyplesin I and its isopeptides from horseshoe crab hemocytes. Chemotherapy. 1991;37:327-34.

69. Chen $Y, X u X$, Hong S, Chen J, Liu N, Underhill CB, et al. RGD-Tachyplesin inhibits tumor growth. Cancer Res. 2001;61:2434-8.

70. Zasloff M. Magainins, a class of antimicrobial peptides from Xenopus skin: isolation, characterization of two active forms, and partial cDNA sequence of a precursor. Proc Natl Acad Sci. 1987;84:5449-53.

71. Moore KS, Wehrli S, Roder H, Rogers M, Forrest JN, McCrimmon D, et al. Squalamine: an aminosterol antibiotic from the shark. Proc Natl Acad Sci. 1993;90:1354-8.

72. Merchant ME, Leger $N$, Jerkins $E$, Mills $K$, Pallansch MB, Paulman RL, et al. Broad spectrum antimicrobial activity of leukocyte extracts from the American alligator (Alligator mississippiensis). Vet Immunol Immunopathol. 2006;110:221-8.

73. Kawabata S, Osaki T, Iwanaga S. Innate immunity in the horseshoe crab. New York: Humana Press; 2003.

74. Kawabata S. Clotting cascade and defense molecules found in the hemolymph of the horseshoe crab. New Directions in Invertebrate Immunology; 1996. p. 255-83.

75. Ehlinger G, Tankersley R. Ecology of horseshoe crabs in microtidal lagoons Boston: Springer; 2009

76. Walls EA, Berkson J, Smith SA. The horseshoe crab, Limulus polyphemus: 200 million years of existence, 100 years of study. Rev Fish Sci. 2002;10:39-73.

77. Mikkelsen T. The secret in the blue blood. Beijing: Science Press; 1988

78. Leibovitz L, Lewbart G. Diseases and symbionts: vulnerability despite tough shells. Cambridge: The American Horseshoe Crab Harvard University Press; 2003. p. 245-75.

79. Marçais G, Kingsford C. A fast, lock-free approach for efficient parallel counting of occurrences of k-mers. Bioinformatics. 2011:27:764-70.

80. Zerbino D, Birney E. Velvet: algorithms for de novo short read assembly using de Bruijn graphs. Genome Res. 2008:gr:074492.107.

81. Boetzer M, Pirovano W. SSPACE-LongRead: scaffolding bacterial draft genomes using long read sequence information. BMC Bioinform. 2014;15:211.

82. Stanke M, Tzvetkova A, Morgenstern B. AUGUSTUS at EGASP: using EST, protein and genomic alignments for improved gene prediction in the human genome. Genome Biol. 2006;7:S11.

83. Altschul SF, Gish W, Miller W, Myers EW, Lipman DJ. Basic local alignment search tool. J Mol Biol. 1990:215:403-10.

84. Jurka J. Repbase update: a database and an electronic journal of repetitive elements. Trends Genet. 2000;16:418-20.

85. Haas BJ, Papanicolaou A, Yassour M, Grabherr M, Blood PD, Bowden J, et al. De novo transcript sequence reconstruction from RNA-seq using the trinity platform for reference generation and analysis. Nat Protoc. 2013:8:1494

86. Larkin MA, Blackshields G, Brown N, Chenna R, McGettigan PA, McWilliam H, et al. Clustal W and Clustal X version 2.0. Bioinformatics. 2007;23:2947-8.

87. Stamatakis A. RAxML version 8: a tool for phylogenetic analysis and postanalysis of large phylogenies. Bioinformatics. 2014:30:1312-3.

88. Wu J, Mao X, Cai T, Luo J, Wei L. KOBAS server: a web-based platform for automated annotation and pathway identification. Nucleic Acids Res. 2006; 34:W720-W4.

89. Xie C, Mao X, Huang J, Ding Y, Wu J, Dong S, et al. KOBAS 2.0: a web server for annotation and identification of enriched pathways and diseases. Nucleic Acids Res. 2011;39:W316-W22.

90. Ai C, Kong L. CGPS: a machine learning-based approach integrating multiple gene set analysis tools for better prioritization of biologically relevant pathways. J Genet Genomics. 2018;45:489-504.

91. Bouckaert R, Heled J, Kühnert D, Vaughan T, Wu C-H, Xie D, et al. BEAST 2: a software platform for Bayesian evolutionary analysis. PLoS Comput Biol. 2014;10:e1003537.

92. Heled J, Drummond AJ. Calibrated tree priors for relaxed phylogenetics and divergence time estimation. Syst Biol. 2011;61:138-49.

93. Hasegawa M, Kishino H, Yano T-A. Dating of the human-ape splitting by a molecular clock of mitochondrial DNA. J Mol Evol. 1985;22:160-74. 
94. Tanaka G, Hou X, Ma X, Edgecombe GD, Strausfeld NJ. Chelicerate neural ground pattern in a Cambrian great appendage arthropod. Nature. 2013; 502:364.

95. Helfrich P, Rieb E, Abrami G, Lücking A, Mehler A. TreeAnnotator: versatile visual annotation of hierarchical text relations. In: Proceedings of the Eleventh International Conference on Language Resources and Evaluation (LREC 2018); 2018.

96. Kumar S, Stecher G, Tamura K. MEGA7: molecular evolutionary genetics analysis version 7.0 for bigger datasets. Mol Biol Evol. 2016;33:1870-4.

\section{Publisher's Note}

Springer Nature remains neutral with regard to jurisdictional claims in published maps and institutional affiliations.

Ready to submit your research? Choose BMC and benefit from:

- fast, convenient online submission

- thorough peer review by experienced researchers in your field

- rapid publication on acceptance

- support for research data, including large and complex data types

- gold Open Access which fosters wider collaboration and increased citations

- maximum visibility for your research: over $100 \mathrm{M}$ website views per year

At BMC, research is always in progress.

Learn more biomedcentral.com/submissions 